\title{
Smoking as a method of coping for medical workers
}

\author{
Lilia Grati \\ Psychology of Development and Psychology of Education Discipline, Department of Applied Pedagogy \\ Ion Creanga State Pedagogical University, Chisinau, the Republic of Moldova
}

Author's ORCID iD, academic degrees and contribution are available at the end of the article

${ }^{\star}$ Corresponding author - Lilia Grati, e-mail: cotelea@mail.ru

Manuscript received May 19, 2021; revised manuscript August 18, 2021; published online September 10, 2021

\begin{abstract}
Background: This article analyzes the professional stress at healthcare professionals (HCP), related to their job. Health care providers can serve as role models in promoting healthy lifestyles; however, HCP commitment to help individuals to quit smoking may be influenced by their own smoking behavior. Material and methods: In order to determine the level of perceptual stress, the Perceived Stress Questionnaire (PSQ) was applied, PSQ developed by Levenstein et al. In order to determine the level of addiction to smoking, the Fagerstorm nicotine addiction test was applied. The research was attended by 210 subjects from 5 medical institutions: doctors, nurses, and resident doctors. Confidentiality is maintained.

Results: The doctors accumulated $32 \%$ on the scale of severe dependence, $8 \%$ moderate dependence and only $9 \%$ mild dependence, after calculating the score and interpreting the data. The resident doctors have accumulated the maximum score on the scale of mild dependence, $7 \%$ moderate dependence and only $3 \%$ severe dependence, which speaks of the fact that they are the youngest category of medical workers at the beginning of their careers and still do not have good defense mechanisms. The nurses, who represent $9 \%$ of the entire group of subjects, accumulated $0 \%$ on the scale of severe dependence, $8 \%$ moderate dependence and $1 \%$ mild dependence.

Conclusions: Comparative data on smoking dependence levels in doctors of $32 \%$ according to the perceived stress level $71 \%$ confirm this. Stressed health workers are more likely to smoke, have different social problems and are males. The results of research have shown that the prevalence of smokers among health care professionals is high (51\%), implying the ineffectiveness of the current government anti-tobacco strategy. Introducing new pillar - Harm Reduction in National Antismoking Action Plan, along with prevention, cessation and protection from second-hand smoking, can improve current smoking situation in general. It would be helpful to implement training programs about Tobacco Harm Reduction for healthcare workers to improve their ability in smoking cessation counselling techniques to provide active support to their patients.

Key words: stress, medical workers, smoking, tobacco harm reduction.
\end{abstract}

Cite this article

Grati L. Smoking as a method of coping for medical workers. Mold Med J. 2021;64(3):16-24. https://doi.org/10.52418/moldovan-med-j.64-3.21.03.

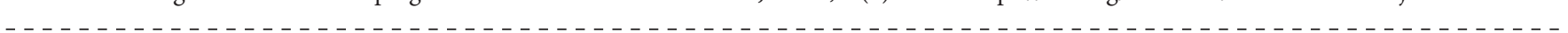

\section{Introduction}

Smoking is the action of "breathing (something) in, inhaling tobacco smoke from a cigarette or pipe; to drink (tobacco), to stink" [1]. The term "smoking" appeared only at the end of the seventeenth century, and until then this action was called "dry drunkenness". The name "nicotine" comes from the name of the French ambassador to Portugal, Jean Nicot, who had received as a gift from some sailors to America some tobacco leaves. He later brought tobacco to the French royal court, from where it later spread throughout Europe [2].

Although everyone knows that smoking causes cardiovascular and respiratory diseases, even cancer, and legislative restrictions have been imposed to combat this addiction, smoking remains one of the daily actions of people on all continents. Globally, the number of smokers has exceeded 1 billion [3], and although in countries with a high standard of living it seems to be declining, globally this figure continues to rise. The worst side is that this habit is addictive, and trying to quit smoking is very difficult, and in most cases leads to withdrawal, the quite excruciating body's condition.

The word "tobacco" comes from the island of Tobago in the Antilles archipelago, where this plant was cultivated, being called "petum" by the natives. The Aztecs and Incas used tobacco mainly during religious ceremonies and it was used as an offering to the gods in purification rituals, which allowed priests or religious leaders to detach themselves from the clarity of mind in order to communicate with the divinity or induce spiritual visions. The tobacco also relieved their hunger and helped them cope better with fatigue [2].

At the beginning of its introduction in Europe, tobacco was a treat only for the nobility, later it began to spread among the needy. This is because smoking tools have started to evolve. If at first the tobacco was crumbled and inhaled or was chewed. Then the pipe was invented, then the cigar, and later the cigarettes. The first cigarette was made in the mid-1800s, and in 1881 the first cigarette maker appeared in 
America. At the beginning of the twentieth century, when the industrial revolution reduced the cost of cigarettes, this habit became common among women. In the interwar period, large cigarette companies were hugely successful in manufacturing more than 300 billion cigarettes a year. By the middle of the twentieth century, half of Europe's adult population was already smokers and tobacco was conquering the planet.

The total number of smokers globally is on the rise. Currently nearly 1 billion people have this habit, according to a study quoted by bbc.co.uk. Although smoking is becoming less popular in many parts of the world, the total number of smokers is on the rise, according to a study conducted by the Institute for Health Metrics and Evaluation (IHME) at the University of Washington, United States, published in JAMA. In 2012, 967 million people smoked every day, compared to 721 million in 1980, according to data collected from 187 countries. Currently, approximately 3 out of 10 men (31\%) and 1 out of 20 women (6\%) smoke daily, compared to 4 out of 10 men $(41 \%)$ and 1 out of 10 women (10\%) in 1980 [4].

\section{Smoking in the Republic of Moldova}

In August 2011, the number of smokers worldwide was estimated at 1 billion [3]. By 2030, it is likely that 10 million people will die from smoking [2]. A turning point in the evolution of the tobacco industry is considered the entry into force on February 27, 2005 of the Framework Convention on Tobacco Control, the first mandatory comprehensive global health treaty [5]. The main provisions of the Convention concern protection against exposure to tobacco smoke; labeling; advertising; liability; illicit trade; rules on tobacco products and taxation. In 2007, Moldova also ratified this Convention, committing itself to comply with the recommendations on smoking cessation [6].

According to a 2010 global survey conducted by the World Health Organization, about 600000 people die each year from passive smoke, a third of who are children who are exposed to cigarette smoke at home [7]. The passive smoking can also cause hearing loss. The World Health Organization declared May 31 "World No Tobacco Day" in 1987, precisely to make smokers aware of the dangers of using tobacco, not only for themselves but also for the society in which they live. The smoking is the most important risk factor for chronic obstructive pulmonary disease.

The study on smoking, conducted by Magenta Consulting on a sample of 1505 respondents, highlighted the fact that our smokers are addicted.

Thus, a smoker from Moldova:

- Smokes on average 17.9 cigarettes per day (67\% increase by 12 persentage points compared to 2012) almost a pack.

- Knows about the harm of smoking, but does not worry that smoking will affect his health in the future.

- Is more reluctant to ban smoking in public places (addiction defense position).

$21 \%$ of survey respondents smoke daily, and $1 \%$ smoke less than daily. Interestingly, by analyzing the socio-demographic profile of the smoker and the non-smoker, Magenta Consulting researchers found that smokers read less often, work more often outdoors, have fewer children and are exposed to cigarette smoke at home and at work to a greater extent [8]. The specialists say that within the stationary IMSP Republican Narcology Dispensary, during 2018, over 460 people received professional counseling to quit smoking, and 305 people received drug treatment for tobacco addiction. More than 3000 smokers received counseling assistance on smoking cessation provided by narcologists from territorial health institutions. Also, the general practitioners provided primary counseling assistance on smoking cessation to more than 156000 smokers. In 2018 alone, out of 500 tobacco addicts who turned to help, 305 quit smoking.

The data of a study conducted by WHO in Moldova show that about $25 \%$ of the population of our republic smoke, hence the fact that almost $44 \%$ are men and 5.6\% women. The data also show that Moldovans start smoking at the average age of less than 18 years [9].

In 2020, this campaign aimed to make young people aware of how dangerous tobacco products are and to prevent the tobacco industry from handling tobacco products. The experts warn that more and more young people smoke hookah, considering it less dangerous, or use menthol cigarettes to mask the use of cigarettes in front of parents, and nicotine from using e-cigarettes is no less dangerous for children's health, it also leads to addiction later. Flavored cigarettes only increase the number of children using tobacco, so that $81 \%$ of young people who have ever used tobacco products started using a flavored product. In this context, in the Republic of Moldova, from May 20, 2020, it is forbidden to place on the market tobacco products with a characteristic menthol flavor. In 2020, along with Armenia, Austria, Finland, Ireland and the United Kingdom, the Republic of Moldova was designated by the World Health Organization as one of the best implementers of tobacco control policies [10].

In 2020, the Deputy Director of the National Agency for Public Health, Ion Salaru, claimed that "smoking is one of the worst public health problems in the Republic of Moldova, because every second smoker dies of a disease caused by this addiction, being fit for work". The consumption of any tobacco product is a major risk factor affecting over 30\% of cancer deaths, $90 \%$ of lung cancer deaths, $25 \%$ of coronary heart disease deaths, $85 \%$ of chronic obstructive pulmonary disease deaths and $25 \%$ of deaths from cerebrovascular disease. Also, smoking severely affects pregnant women, causing premature births and low birth weight, and increases the risk of sudden infant death syndrome in newborns. As a result, out of 38000-39000 people who die annually, over 4500-4700 (about 14\%) die from diseases caused by tobacco use, including over $60 \%$ of people of working age, the mortality among men being 2 times higher than women. Since August 2020, in order to reduce the advertising and promotion of tobacco products, the visible display of tobacco 
products and related products, devices and accessories for their use, recharging or heating in commercial spaces accessible to the public was prohibited. The provisions of Article 25(5) of Law 278/2007 took effect from August 15, 2020 in order to reduce their promotion among young people. The law was on tobacco control concerning the prohibition of visible exposure of tobacco and related products, devices and accessories for their use, recharging or heating in commercial spaces accessible to the public. Between August 17 and September 25, 2020, several unannounced checks were organized, establishing that $90 \%$ of the audited economic agents complied, and sanctions were applied until they fully complied with the legal provisions [11].

\section{Stressors and explanatory-interpretative models of} organizational stress

According to the concept of the Canadian scientist Hans Selye [12], launched in 1936, stress is the non-specific reaction of the body to any request, a concept that quickly became established in the international language. Thus, this notion is quickly imposed in everyday circulation. At the same time, it refers to the real and the imaginary stress, which must be well differentiated.

The dictionary of social psychology defines the term psychic stress as a state of tension, straining and discomfort, caused by emotional agents, with negative significance, frustration or depression of states of motivation (needs, desires, and aspirations), difficulty or the impossibility of solving some problems [13].

In the current conditions of life, we have another form of stress that occupies a leading place in these classifications, namely organizational stress, or stress at work. It is the most harmful result, having a negative impact, but also a positive one, both physically and mentally. At the base of the organizational stress, there are 2 stressors of a psychological nature:

1. Role conflict (when a person is subject to requests between the manager and the co-workers)

2. Ambiguity of the role (when a person does not have enough information to perform their function)

The workplace stressors include:

1. Stressors at executive and managerial level (role overload, very high responsability towards employees)

2. Operational stressors (unpleasant or even dangerous working conditions)

3. General stress factors (interpersonal conflicts, intergroup quarrels)

The effects of stress in general could be grouped into 5 main categories :

- Subjective effects: anxiety, aggression, indifference, fatigue, malaise, decreased self-confidence, nervousness, feelings of loneliness;

- Behavioral effects: impulsive behavior, emotional disorders, predisposition to mistakes, alcohol and coffee abuse, tendency to eat and /or smoke excessively;

- Cognitive effects: decreased ability to make rational decisions, lack of concentration, decreased attention, hypersensitivity to criticism, mental blockages;
- Psysiological effects: increase in pulse, blood pressure, blood sugar, dry mouth, cold sweats;

- Organizational effects: low efficiency, isolation, lack of job satisfaction, absenteeism, reduced responsibility, decreased loyalty to the organization, resignations.

The most common effects of stress felt on the employee and the organisation:

1. The fatigue distinctive for the organizational stress:

a) Alarm phase (iritability, susceptibility...),

b) Agitation phase (lack of trust in others, a kind of malice towards others...),

c) Exhaustion phase (depression, isolation...).

2. Overworking (as a form of chronic fatigue).

3. Fluctuation of staff.

4. Alcoholism.

Smoking as a strategy of overcoming the occupational stress of the medical staff

Smoking is considered by smokers as a method of combating stress, thereby adding another excuse to quit smoking. This habit can also reduce stress. The ensemble of studies to date suggest that under certain conditions nicotine can act as an anxiolytic and an antidepressant, but that following chronic use, adaptations to nicotine can occur resulting in increased anxiety and depression following withdrawal [14].

Nicotine effects on mental state may vary. First, by causing the release of glucose from the liver and adrenaline (epinephrine) from the adrenal medulla, it induces excitation. From a subjective point of view, reported by smokers, this manifests itself in relaxation, calmness and liveliness. A mildly euphoric state has also been reported, due to endorfin euphoria. Decreased appetite and increased metabolism can result in weight loss in some smokers [15].

Scientists from the University of New York have found that nicotine compensates for brain defects in schizophrenia. It is no coincidence that $88 \%$ of Americans with this disease smoke, and a lot [16].

Despite the addiction of nicotine, it still has a positive property. But such it is not for mentally healthy people, but for people suffering from schizophrenia - nicotine increases their mental activity. Following such a report from researchers in the United States, the medical community released a drug with an effect similar to nicotine to avoid the health damage from smoking [17].

There are doctors among the smokers. Why? They are humans too. The main reasons for smoking in the present study were relaxation and fighting stress, and the cultural misconception of tobacco as a "socializer or helper" under some psychologically stressful conditions is indicated. The latter indicates the influence of cultural and environmental factors as well as personal or individual handicaps [18].

The doctors, the people who are best informed about the harm of smoking, are no exception to this habit. They also smoke, because here prevails the ordinary man, not the doctor. The doctors still believe that smoking a cigarette can relieve you of stress at work, as they are always in contact with different people. A doctor, when asked why he smokes, 
will always say that he does it by habit, that he is very nervous, that he relaxes, and, of course, that it is a habit that will not last long and he can give it up whenever he wants. Also, he will be the one who will not recommend smoking to other people, saying that this addiction brings enormous damage to health. A doctor will always ask his patient if he smokes to find out the cause of the disease, or if smoking has worsened the patient's health, and will ask him to give up this habit, listing all the negative effects of harmful substances from the smoke to the body. But, then why does a doctor smoke? The doctors' attitude towards smoking does not differ significantly from the position of ordinary people despite the colossal baggage of knowledge, experience and work practice. The most interesting thing is that just doctors who smoke could answer the questions which are the pathologies tobacco smoking could lead to. According to some data, the doctors spend a lot of time to initiate measures to combat smoking, but they will still smoke. The average age of initiation of smoking among the doctors is 21 years. Thus, many of them start smoking since adolescence or after they enter the university [18].

So why the doctors smoke, according to their opinion:

- The medicine occupies leading positions if we classify professions according to their complexity;

- The mental and emotional stress if you have to prescribe treatments to people and are afraid of making mistakes;

- The increased flow of patients lately with a multitude of difficult situations;

- The abundance of documents to be completed, instead of actual work;

- In order to calm down after realization of professional duty (e.g. difficult operation);

- For the ride, socialization, so that you do not distinguish yourself from friends/colleagues/superiors who smoke;

- The negative influence of the family in which the closest relatives smoke;

- The desire to try smoking;

- The pleasure from smoking;

- The stress during working hours;

- The recreation.

Although there are many ways to combat stress at work and find peace of mind, such as walking to work, reading books in your free time, listening to music, they are not taken into account. As an excuse, it is called lack of time, while smoking a single cigarette for 2-3 minutes calms your nerves and calms you down. Like any person, the doctor will start to feel stressed shortly after smoking a cigarette but will always find other excuses. Although doctors know best the negative effects of smoking to the body by detecting pathologies associated with tobacco use, they smoke.

Many of them start smoking since university, because the professor-doctor smokes, his medical colleagues smoke, because many medical professionals smoke and they are absolutely healthy, because they want to feel equal in front of them. Many of them, like other people in different fields, think that they can quit smoking at any time, which unfortunately does not happen, because they have also formed a habit of smoking during a short break, after breakfast, or in a stressful situation. Of course, medical activity is associated with great psycho-emotional stress due to daily communication with a large number of patients, each coming not only with his health problems, but also with his negative load sometimes, the abundance of documents, clinical situations that require much physical and emotional effort, and in the process of treatment there are also negative patient-doctor relationships due to aggression, or even hatred from some patients, or even colleagues, situations that increase the level of stress, and it leads to smoking. All this leads in time to the burnout syndrome, from where later doubts can arise regarding the correctness of choosing the profession, and some of them see tobacco use as a quick treatment [19].

However, why do some doctors smoke and others do not? Because some people also have an unconscious feeling of superiority over their colleagues, with the illusion that they can quit smoking at any time, that they have complete control over their health, but they forget that from a biological point of view, he is the same person as the others, and nicotine has the same euphoric effects on everyone. The doctors oppose smoking, because the highest mortality rate is noted among them, however they do not stop smoking themselves: at the entrance to the hospital, dental clinics, etc. By trusting people in white robes, a false trust is formed in the benefits that tobacco can bring to the body. In order to prevent smoking, in China, for example, smoking doctors are deprived of the right to practice medicine. The doctors' recommendations regarding smoking cessation are viewed with reluctance, because those who are so much against smoking after the job or even during job smoke. And the worst thing is that among the doctors who smoke there are not only men, but also women [20].

And because doctors are humans, and they understand very well the harm that tobacco and nicotine do to the body, they should also fight this addiction through the same methods they recommend to their patients: a balanced lifestyle characterized by physical activity, intake of nutrients from fruits and vegetables, social interactions beneficial to the spirit, positive attitude towards oneself and those close to them, proper nutrition, ensuring 8 hours of peaceful sleep every night, combating stress through methods other than smoking.

Nicotine is not the cause of the disease, combustion is

Nicotine is found naturally in the tobacco plant. Once inhaled, the substance is absorbed through the lungs directly into the bloodstream, from where it is transported through the body to tissues and organs, including the brain. Here, the nicotine binds to certain receptors and triggers the release of dopamine and other neurotransmitters. Thus, the nicotine can stimulate but also affect short-term brain functions, such as emotions, learning ability and memory. Finally, prolonged exposure to nicotine increases the body's 
tolerance to this substance and becomes addictive to the point where smoking cessation becomes extremely difficult to achieve.

Nicotine is addictive. According to a report by the Royal College of Physicians [21], nicotine increases heart rate and blood pressure and has a number of local irritating effects, but is not carcinogenic. There are three deadly conditions associated with smoking - lung cancer, which results mainly from direct exposure of the lungs to carcinogens in cigarette smoke, chronic obstructive pulmonary disease caused by irritating and inflammatory effects of smoke, and cardiovascular diseases, which are caused by the effects of smoke on vascular clotting and walls of blood vessels. None are caused primarily by nicotine.

In practical terms, as Mike Russell argued in the 1970s, "smokers smoke for nicotine, but are killed by tar" [22]. And the health effects of this tar are quite serious:

Very short-term negative effects. A few minutes after the first smoke:

- Heart rate accelerates;

- Laryngeal tissue becomes irritated;

- Carbon monoxid enters the blood;

- Carcinogens enter the lungs immediately;

- Air is polluted;

- Eyes may be irritated;

- Skin temperature drops.

\section{Medium and long-term effects:}

- Smoking is responsible for $80-90 \%$ of chronic bronchopneumopathy;

- Smoking is responsible for $85 \%$ of bronchopulmonary cancers;

- Smoking is responsible for $30 \%$ of deaths from cardiovascular disease;

- Carbon monoxide in cigarette smoke increases the level of cholesterol in the blood, which eventually leads to its deposition on the walls of blood vessels;

- Smoking increases the risk of cancer of the lips, tongue, salivary glands, mouth, larynx, esophagus and pharynx;

- Gastric cancer is alo associated with smoking;

- Smoking represents a risk factor, for bladder, kidney, cervical and pancreatic cancer;

- There is a strong addictive relationship between smoking and leukemia;

- In women who smoke, menopause sets in on average 5 years earlier than in non-smokers;

- Smoking can cause hormonal dysfunctions in reproductive system;

- Risk of osteoporsis is increased in women who smoke;

- Sperm mobility is slow in men who smoke.

Although many people remain relentless when it comes to quitting smoking, there are also among those who every morning when they wake up aim to quit this bad habit. Over the years, authorities in several countries have proposed measures to combat tobacco use, to reduce the number of smokers, by banning smoking in public places, printing slogans about the damage of nicotine to health even on cigarette packs, etc. Because, the number of smokers is still growing, they feel compelled to find alternative methods to regular cigarettes, especially since it has been shown that not so much nicotine is harmful to health as the process of burning tobacco. Thus, among the anti-smoking strategies, a series of nicotine-based products (patch, chewing gum, snus, electronic cigarettes, tobacco heaters) are proposed for those who have not been able to quit smoking permanently. Of course, complete smoking cessation would be the best alternative, because only that would eliminate the negative effects of smoking on health [23]. Hence, the dilemma of doctors is what to propose to humanity: quit smoking or alternative methods.

For example, some people smoke, being convinced that this habit relieves them of stress. Although, this is only a momentary effect, just as a simple cigarette does not drive away the problems we face, but, on the contrary, creates other health problems. Jean Gehricke [24], from the University of California has shown that nicotine does have calming effects on angry people, and they tend to smoke even more, becoming addicted to smoking. Others smoke because they have tried the effect of nicotine on the body in adolescence, and later became addicted.

\section{Material and methods}

At the first stage, the Perceived Stress Questionnaire (PSQ), developed by Levenstein and his collaborators [25], was applied as a research tool and aims to determine the level of perceived stress. The test contains 30 items, and the subjects were asked to read each item in turn, awarding the corresponding score by choosing a single answer for each item: almost never -1 point, sometimes -2 points, often 3 points, usually -4 points. For questions number $1,7,10$, $13,17,21,25,29$ - the score is reversed: almost never - 4 points, sometimes -3 points, often -2 points, usually -1 point. The score between 30 and 120 allows falling into one of the 3 categories: $30-59$ - low stress level; 60-89 - moderate stress level; 90-120 - high stress level. There is no time limit for this test.

The sample was formed of 210 medical workers aged between 20 and 61 years. The medical workers were divided into 3 categories: doctors, resident doctors and nurses.

Analysing the data in the table above, we see that resident doctors have obtained the highest percentage of intense stress, which speaks of the fact that they are still at the beginning of their career, showing some anxiety about the decisions made, not yet having well-formed coping mechanisms. The nurses follow with $86 \%$, which speaks about the emotional and physical load they face, direct contact with the patient and the large volume of work. Doctors accumulated $71 \%$, a lower percentage, which can be explained by the fact that they have a higher level of resilience due to work experience and seniority (fig. 1). 


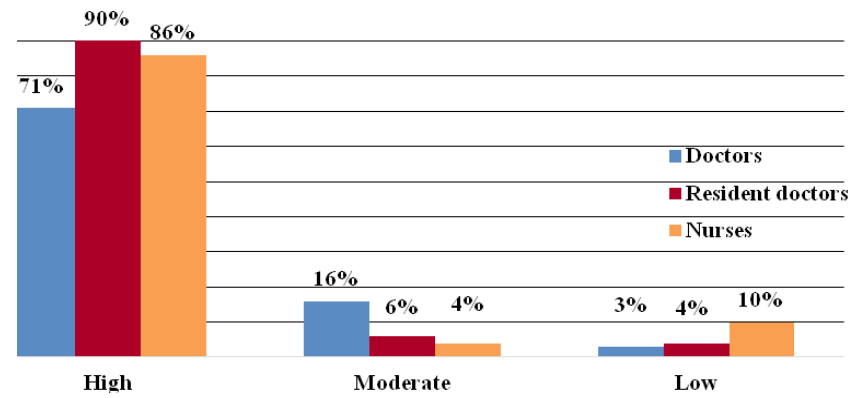

Fig. 1. Distribution of the total score for stress perception levels in medical workers

At the second stage, the Fagerström Test for Nicotine Dependence was applied. The purpose of the test is to determine the level of nicotine dependence. The test was applied only to smokers (108 subjects). It contains 6 questions, each question having three answer options. Subjects were asked to choose only one of the three options. The score and interpretation were calculated according to the scale: $7-10$ points - high dependence, 4-6 points - moderate dependence, 0-3 points - low dependence. The subjects had no time limit, and confidentiality was maintained (tab. 1).

Table 1. Smoking dependence according to the categories of medical workers

\begin{tabular}{|l|c|c|c|c|}
\hline $\begin{array}{c}\text { Category of } \\
\text { medical workers }\end{array}$ & $\begin{array}{c}\text { Total } \\
\text { number }\end{array}$ & $\begin{array}{c}\text { High de- } \\
\text { pendence }\end{array}$ & $\begin{array}{c}\text { Moderate } \\
\text { dependence }\end{array}$ & $\begin{array}{c}\text { Low de- } \\
\text { pendence }\end{array}$ \\
\hline Doctors & 55 & $32 \%$ & $8 \%$ & $9 \%$ \\
\hline Resident doctors & 44 & $3 \%$ & $7 \%$ & $32 \%$ \\
\hline Nurses & 9 & $0 \%$ & $8 \%$ & $1 \%$ \\
\hline
\end{tabular}

Following the results obtained, we can say that people with smoking dependence do not do this for pleasure but in order to avoid the discomfort caused by resistance, and medical workers start smoking more intensely when they accumulate internal tension (caused by a complicated intervention or when they had a busier working day, not to mention medical errors (malpractice) accompanied by remorse and guilt complexes (fig. 2).

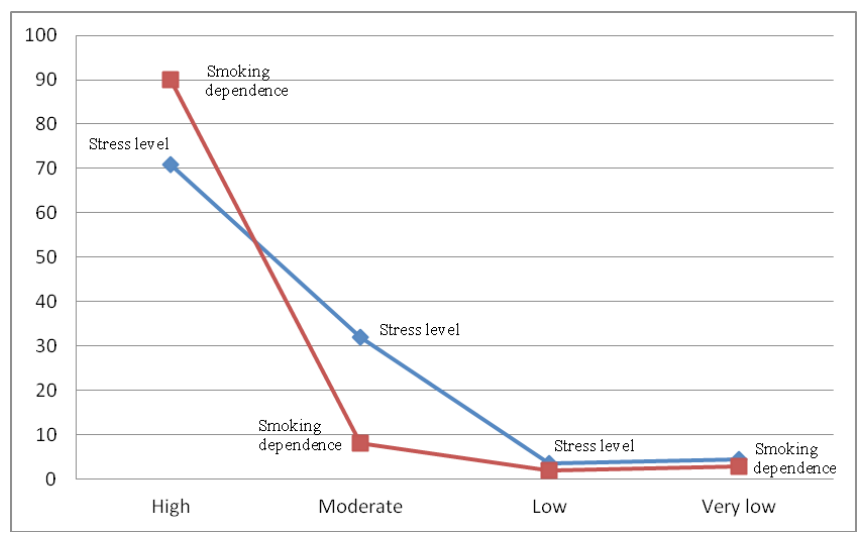

Fig. 2. Comparative data on the level of smoking dependence according to the level of perceived stress
It goes without saying that in the face of such a threat, any medical professional creates his/her own defence mechanisms (increasing the number of coffee drinks, alcohol consumption, sedatives, the number of cigarettes smoked) which are harmful forms of coping with stress they face.

Alternative smoking cessation solutions include:

- Electronic cigarettes;

- Chewing gum with nicotine;

- Nicotine patch;

- Nicotine nasal sprays;

- Snus;

- Tabacco heaters;

- Behavioral counselling;

- Financial rewards for quitting smoking.

Electronic cigarette - is a product designed to work with nicotine or other substances in the form of vapors. Its role is to mimic the experience of real smoking, in conditions less harmful to health. In many cases it is also used to quit smoking. It can overcome withdrawal symptoms when someone tries to quit smoking. In addition, e-cigarette users can choose between low-nicotine cartridges or even nicotine-free liquids [26].

Tobacco Heating System - or THS heats a specially formulated tobacco material using an electronically controlled heater to temperatures below that necessary to initiate combustion. The controlled heating of the tobacco material vaporizes water, glycerol (an aerosol former added to the tobacco material), nicotine an aerosol that is not smoke, and that is fundamentally different in origin, chemical and physical composition to cigarette smoke. As the tobacco material in the Tobacco Stick is heated and not burned, the aerosol generated contains on average 90 to $95 \%$ lower levels of harmful and potentially harmful constituents compared to the mainstream smoke of a standard cigarette [27].

Nicotine gum is used in the treatment of nicotine addiction by satisfying the exaggerated demand for nicotine and the symptoms of smoking cessation. [36]. Nicotine withdrawal occurs when the body no longer receives nicotine from tobacco. By administering nicotine gum, the body receives a low dose of nicotine, and decreases the risk of withdrawal symptoms, helping to quit smoking more easily. This gum contains $2 / 4 \mathrm{mg} / \mathrm{pc}$ of nicotine, compared to $6-8 \mathrm{mg}$ compared to a cigarette. Nicotine is absorbed more slowly when chewed (90\% in 20-30 minutes). It is recommended to use for 3-6 months. After a year of treatment, combined with other methods of therapy, $30 \%$ managed to quit smoking. Without psychotherapy and medical advice, success is low [28].

Nicotine patch is a patch that sticks to the skin, which releases nicotine into the body through it. It is used in nicotine replacement therapy (NRT) and is considered along with nicotine chewing gum one of the safest NRTs available for the treatment of tobacco use disorders. It is usually worn for 16-24 hours and can be removed during sleep. Research has shown that NRT in combination with cognitive behavioral therapy can improve smoking quitting rates in pregnant women. Nicotine patches are also being studied to help relieve the symptoms of postoperative pain and to treat early 
dementia, anxiety, depression and inattention in subjects with attention deficit hyperactivity disorder [28].

Nicotine nasal spray - acts on the need to smoke in 60 seconds. It is used to help a person when he wants. This is a type of treatment called Nicotine Replacement Therapy (NRT). By using this spray, the human body continuously receives a small amount of nicotine for a short period of time. It is less harmful than smoking. This is because it does not contain tar, carbon monoxide or other toxins from cigarette smoke [28].

Snus - is a type of smokeless tobacco product. It is a crushed wet tobacco, which is placed between the upper lip (less often - lower) and the gum for a long time - from 30 to $60-70$ minutes (according to the manufacturers, from 5 to 30 minutes). In this case, nicotine from the tobacco enters the body. Snus belongs to smokeless tobacco (this group also includes dry and wet snuff, chewing tobacco, etc.). It is characterized as a type of wet snuff with high nicotine content and a low content of carcinogens. It has been known in Sweden since 1637 . It is produced and consumed mainly in this country (which is why it is often called Swedish snus). The EU (with the exception of Sweden) has banned the sale of snus since 1992, although its use is not restricted. Snus is legally sold in Sweden, Hungary, Denmark and Norway [29].

Behavioral counseling - permanent smoking cessation becomes more productive when you have someone close to whom you can talk and who can support you. These people include professionals from among doctors, psychologists, people who have already given up smoking, relatives [30].

Financial rewards for quitting smoking - when a person receives a sum of money just to quit smoking, he also receives psychological satisfaction. This reward can consist of cash or vouchers, offered by the managers of the institutions in which the person operates, if this institution aims to combat this vice, or even by the government, as a method of combating tobacco.

Although more and more people are trying to quit smoking, every second smoker returns to the old habit in 3-7 days, claiming that he has not found a good reason to quit smoking, does not have the will or feels very stressed because of smoking quitting. Sudden smoking quitting is quite difficult, and about $95 \%$ of those who try to quit smoking once and for all alone, without the help of a doctor's conciliation, soon return to the old habit [26].

\section{Discussion}

Veronica Gasca conducted a similar study on a sample of 61 people, represented by medical workers from the Chisinau Municipal Public Health Centre and the National Public Health Centre. The applied questionnaire included several groups of symptoms. The intellectual symptoms caused by stress specified by medical workers referred to making difficult decisions $(27.9 \%)$, often being distracted (26.2\%) and concentrating around a single problem (24.6\%). Among the behavioural symptoms caused by stress, the respondents more frequently highlighted the chronic lack of time (42.6\%) and little time of communication with family and friends $(26.2 \%)$. A share of $21.3 \%$ of respondents felt increased distress and anxiety, which refers to emotional symptoms. Among the physiological symptoms, more frequently the medical workers felt fatigue (42.6\%), had problems from the circulatory system $(27.9 \%)$ and headaches or aches in different parts of the body with indeterminate character (26.2\%). An impressive number of health workers is affected by occupational stress, which has adverse health consequences [31].

Occupational stress ranks second in the hierarchy of occupational health problems in EU countries, after osteomuscular disorders. A pilot study of the European Agency for Safety and Health at Work, conducted in 2001, shows that over 25\% of Western Europeans working in healthcare field have stress problems. And among them, the most affected are doctors in the primary care sector. $\mathrm{He} /$ she is most often required by situations to act effectively. The family doctor bears, like everyone else, the stressors existing in society.

Smoking is one of the oldest habits in the world and one of the strongest factors that leads to serious consequences of illness. Trying to prevent or stop smoking at an early stage is much easier than when it becomes addictive. Many people who are addicted to smoking do so out of pleasure but to avoid the discomfort caused by resistance.

Smoking kills one-third to one-half of the total number of smokers each year, which is the leading cause of illness and mortality in the world. One problem is that smoking is also widespread among medical workers who start smoking more intensely when they accumulate internal tension (caused by a complicated intervention or when they have had a busier work day, not to mention the medical errors (malpractice) accompanied of remorse and guilt complexes).

It goes without saying that in the face of such a threat, any medical professional creates his own defense mechanisms (increasing the number of coffee drunk, alcohol consumption, sedatives, the number of cigarettes smoked) which are harmful ways to deal with in the front of stress.

Health care professionals are familiar with the harmful effects of smoking and passive smoking. But in fact they usually smoke in front of their patients and kids [32]. Almost all of the examinees (198) agree with the claim that the medical health professionals have an ethical responsibility to warn pregnant women who smoke of the potentially harmful effects smoking can have on the fetus during pregnancy. Those are results similar to other studies where physicians showed willingness for a conversation with a pregnant woman about adverse effects of smoking and advising about cessation [33].

The great number of physicians completely agrees that healthcare professionals have an ethical responsibility to warn smokers of the harmful effects of smoking. However, health care professionals who smoke feel discomfort in situations when they are supposed to counsel their patients about smoking cessation and the harmfulness of the tobacco smoke [34].

They have difficulties in creating transfer/countertransference relationship with patients in the smoking prevention [35]. Problems can also be caused by the lack of motivation of the health care professionals due to previous negative 
experiences when patients didn't accept the advice given by them regarding the use of tobacco products for cessation.

To prevent such issues in the future and minimize negative experience, healthcare workers should be informed about Tobacco Harm Reduction (THR) concept.

THR is a public health strategy to lower the health risks to individuals and wider society associated with using tobacco products. It is an example of the concept of harm reduction, a strategy for dealing with the use of drugs, and reducing smoking is vital to public health.

Clearly then, traditional tobacco control interventions elaborated in the WHO Framework Convention on Tobacco Control (FCTC) are not enough. Tobacco harm reduction (THR) policies therefore should be regarded as complementary rather than inimical to reducing the global death and disease from smoking [36].

The glimmer of hope is that some countries have taken a more inclusive approach to THR as part of the overall strategy towards a smoke-free world.

Recent published data from the Global Burden of Disease Study - Age-standardised prevalence of current smoking tobacco use in 2019 and percentage change in agestandardised prevalence of current smoking tobacco use in 1990-2019 among individuals aged 15 years [36] reveal that the largest decreases in age-standardised prevalence of smoking tobacco use were observed in Brazil - 73.4\%, Norway - 53.5\%, Denmark - 49.3\%, Iceland - 49.7\%, Japan $-32.6 \%$.

All these countries are members of WHO FCTC and succefuly implemented all necessery tobacco control strategies (increasing taxation, display ban, public places smoking restrictions and etc) but not only. At the same time they accepted THR concept and introduced it in legislation in different way:

Brasil - e-cigarettes are allowed as smoking cessation devices. In Norway and Denmark - traditionally use snus. In 2018, the Norwegian Public Health Institute issued a report evaluating harm reduction as a strategic element of tobacco control policy and assessing the pros and cons of the availability of less risky nicotine-containing alternatives compared to cigarettes. The institute concluded that preventing access to less risky nicotine-containing products can paradoxically entrench the position of the most hazardous product, i.e., cigarettes [37].

Iceland - a study from Iceland's Directorate of Health shows that smoking in Iceland is on the decline, with evidence that the use of e-cigarettes is contributing to a decrease in the consumption of traditional cigarettes. The study indicates that last year daily smoking fell to 9 percent of population, a drop of 5 percent in three years, while daily e-cigarettes use reached 4 percent.

Japan - Cummings et al. also reported that from 2011 to 2016 , sales of cigarettes declined by about $2 \%$ to $4 \%$ annually, while a decline of $13 \%$ in cigarette sales occurred in $2017,12 \%$ in 2018 , and $9 \%$ in 2019 , indicating a much more significant decline over this period. Between 2015 and 2019, the period when THS was introduced in the market, total cigarette sales dropped by $34 \%$. It is likely that the introduc- tion of HTPs in Japan has caused a significant decline in cigarette sales [38].

The best thing that adult smokers can do to improve their health is to quit tobacco and nicotine use altogether. For smokers who don't quit, the health impacts of cigarette smoke can be greatly reduced if they switch completely to a less harmful alternative and stop smoking.

\section{Conclusions}

The results of this study reveal that smoking dependence is directly related to the level of perceived stress. Comparative data on smoking dependence levels in doctors of $32 \%$ according to the perceived stress level $71 \%$ confirm this. Stressed health workers are more likely to smoke, have different social problems and are males. Physicians and nurses, as a part of the health care system, play an equally important role in the prevention and education of patients about the harmfulness of smoking. The results of research have shown that the prevalence of smokers among health care professionals is high (51\%), implying the ineffectiveness of the current government anti-tobacco strategy. Health care professionals, who should inform others about the harmfulness of the tobacco smoke, are not fully aware to what extent smoking is harmful both to them and to people who surround them. Introducing new pillar - Harm Reduction in National Antismoking Action Plan, along with prevention, cessation and protection from second-hand smoking, can improve current smoking situation in general. It would be helpful to implement training programs about Tobacco Harm Reduction for healthcare workers to improve their ability in smoking cessation counselling techniques to provide active support to their patients. Regulatory bodies should give medical workers possibility to develop healthy coping strategies to prevent and overcome occupational stress such as: an extensive process of introspection; examining the lifestyle, one's own motivations, priorities; development of strategies for stress control; application of time management strategies; use of systematic physical training for effort capacity.

\section{References}

1. Doll R. Uncovering the effects of smoking: historical perspective. Stat Methods Med Res. 1998;7(2):87-117. doi: 10.1177/096228029800700202.

2. Charlton A. Medicinal uses of tobacco in history. J R Soc Med. 2004 Jun;97(6):292-6. doi: 10.1258/jrsm.97.6.292.

3. Mishra A, Chaturvedi P, Datta S, Sinukumar S, Joshi P, Garg A. Harmful effects of nicotine. Indian J Med Paediatr Oncol. 2015;36(1):24-31. doi: 10.4103/0971-5851.151771.

4. Ng M, Freeman MK, Fleming TD, et al. Smoking Prevalence and Cigarette Consumption in 187 Countries, 1980-2012. JAMA. 2014;311(2):183-192. doi: 10.1001/jama.2013.284692.

5. Zhou SY, Liberman JD, Ricafort E. The impact of the WHO Framework Convention on Tobacco Control in defending legal challenges to tobacco control measures. Tob Control. 2019;28(Suppl 2):s113-s118. doi: 10.1136/ tobaccocontrol-2018-054329.

6. The Republic of Moldova, The Parliament. Legea nr. 124 din 11.05.2007 pentru ratificarea Convenției-cadru a Organizației Mondiale a Sănătății privind controlul tutunului [ LAW No 124 of 11.05 .2007 for the ratification of the Framework Convention of the World Health Organization on tobacco control]. Monitorul Oficial al Republicii Moldova. 2007;(7881):art. 362. Romanian. 
7. Oberg M, Jaakkola MS, Woodward A, Peruga A, Prüss-Ustün A. Worldwide burden of disease from exposure to second-hand smoke: a retrospective analysis of data from 192 countries. Lancet. 2011 Jan 8;377(9760):13946. doi: 10.1016/S0140-6736(10)61388-8.

8. Magenta Consulting. Cercetare Magenta: Fumătorii fumează și mai mult, iar numărul nefumătorilor crește [Magenta Research: Smokers smoke even more, and the number of non-smokers increases] [Internet]. Chisinau; 2014 [cited 2021 Apr 9]. Available from: https://consulting.md/rom/ statistici-si-publicatii/cercetare-magenta-fumatorii-fumeaza-si-mai-multiar-numarul-nefumatorilor-creste. Romanian.

9. World Health Organization. Tobacco Control Fact Sheet: The Republic of Moldova. Geneva: WHO; 2016.

10. Ministry of Health, Labour and Social Protection of the Republic of Moldova. Încurajăm pe toți să educăm și să creăm o generație fără tutun [We encourage everyone to educate and create a tobacco-free generation] [Internet]. Chisinau: The Ministry; 2020 [cited 2021 Apr 9]. Available from: https://msmps.gov.md/comunicare/incurajam-pe-toti-sa-educamsi-sa-cream-o-generatie-fara-tutun/. Romanian.

11. Salaru I. Fiecare al doilea fumător moare de o boală provocată de acest viciu [Every second smoker dies from a disease caused by this addiction] [Internet]. Chisinau; 2021 [cited 2021 Jun 3]. Available from: http:// amtbuiucani.md/2021/06/02/ion-salaru-fiecare-al-doilea-fumator-moarede-o-boala-provocata-de-acest-viciu/. Romanian.

12. Tan SY, Yip A. Hans Selye (1907-1982): founder of the stress theory. Singapore Med J. 2018;59(4):170-171. doi: 10.11622/smedj.2018043.

13. Monroe SM, Cummins LF. Stress: psychological perspectives. In: Wright JD, editor. International Encyclopedia of the Social and Behavioral Sciences. 2nd ed. Oxford: Elsevier; 2015. p. 583-587. https://doi.org/10.1016/ B978-0-08-097086-8.25038-1.

14. Picciotto MR, Brunzell DH, Caldarone BJ. Effect of nicotine and nicotinic receptors on anxiety and depression. Neuroreport: 2002 July 2;13(9):10971106. doi: 10.1097/00001756-200207020-00006.

15. Jiloha RC. Biological basis of tobacco addiction: Implications for smoking-cessation treatment. Indian J Psychiatry. 2010;52(4):301-307. doi: 10.4103/0019-5545.74303.

16. Lucatch AM, Lowe DJE, Clark RC, Kozak K, George TP. Neurobiological determinants of tobacco smoking in schizophrenia. Front Psychiatry. 2018;9:672. doi: 10.3389/fpsyt.2018.00672.

17. Kutlu MG, Parikh V, Gould TJ. Nicotine addiction and psychiatric disorders. Int Rev Neurobiol. 2015;124:171-208. doi: 10.1016/ bs.irn.2015.08.004.

18. Mahfouz AA, Shatoor AS, Al-Ghamdi BR, Hassanein MA, Nahar S, Farheen A, Gaballah II, Mohamed A, Rabie FM. Tobacco use among health care workers in Southwestern Saudi Arabia. BioMed Res Int. 2013;2013:960292. https://doi.org/10.1155/2013/960292.

19. Vogt F, Hall S, Marteau TM. General practitioners' and family physicians' negative beliefs and attitudes towards discussing smoking cessation with patients: a systematic review. Addiction. 2005 Oct;100(10):1423-31. doi: 10.1111/j.1360-0443.2005.01221.x.20.

20. Pinget C, Martin E, Wasserfallen JB, Humair JP, Cornuz J. Cost-effectiveness analysis of a European primary-care physician training in smoking cessation counseling. Eur J Cardiovasc Prev Rehabil. 2007 Jun;14(3):451-5. doi: 10.1097/HJR.0b013e32804955a0.

21. Royal College of Physicians. Nicotine without smoke: Tobacco harm reduction. London: RCP; 2016. 191 p.

22. Fiore M, Baker T. Reduced-nicotine cigarettes - promising regulatory pathway. N Engl J Med. 2015;373(14):1289-1291. doi: 10.1056/NEJMp1509510.
23. Baumeister RF. Addiction, cigarette smoking, and voluntary control of action: Do cigarette smokers lose their free will? Addict Behav Rep. 2017;5:67-84. doi: 10.1016/j.abrep.2017.01.003.

24. Gehricke JG, Potkin SG, Leslie FM, Loughlin SE, Whalen CK, Jamner LD, Mbogori J, Fallon JH. Nicotine-induced brain metabolism associated with anger provocation. Behav Brain Funct. 2009;5:19. doi: 10.1186/1744-90815-19.

25. Fliege H, Rose M, Arck P, Walter OB, Kocalevent RD, Weber C, Klapp BF. The Perceived Stress Questionnaire (PSQ) reconsidered: validation and reference values from different clinical and healthy adult samples. Psychosom Med. 2005 Jan-Feb;67(1):78-88. doi: 10.1097/01.psy.0000151491.80178.78.

26. Rahman MA, Hann N, Wilson A, Mnatzaganian G, Worrall-Carter L. E-cigarettes and smoking cessation: evidence from a systematic review and meta-analysis. PLoS One. 2015;10(3):e0122544. doi: 10.1371/journal. pone. 0122544 .

27. Jaccard G, Tafin Djoko D, Moennikes O, Jeannet C, Kondylis A, Belushkin M. Comparative assessment of HPHC yields in the Tobacco Heating System THS2.2 and commercial cigarettes. Regul Toxicol Pharmacol. 2017 Nov;90:1-8. doi: 10.1016/j.yrtph.2017.08.006.

28. Balbani AP, Montovani JC. Methods for smoking cessation and treatment of nicotine dependence. Braz J Otorhinolaryngol. 2005;71(6):820-826. https://doi.org/10.1016/S1808-8694(15)31254-4.

29. Clarke E, Thompson K, Weaver S, et al. Snus: a compelling harm reduction alternative to cigarettes. Harm Reduct J. 2019;16(1):62. https://doi. org/10.1186/s12954-019-0335-1.

30. Hosford RE. Behavioral counseling - a contemporary overview. Counseling Psychologist. 1969;1(4):1-33. doi: 10.1177/001100006900100402.

31. Gasca V. Simptomele stresului ocupațional la lucrătorii medicali [Symptoms of occupational stress of medical workers]. In: SUMPh Nicolae Testemitanu. Collection of scientific summaries of students, residents and young researchers. Chisinau: Medicina; 2015. p. 268. Romanian [cited 2021 May 9]. Available from: http://repository.usmf.md/bitstream/20.500.12710/2263/1/SIMPTOMELE_STRESULUI_OCUPATIONAL_LA_LUCRATORII_MEDICALI.pdf

32. Duaso M, Duncan D. Health impact of smoking and smoking cessation strategies: current evidence. Br J Community Nurs. 2012;17(8):356-63.

33. Glover M, Paynter J, Bullen C, Kristensen K. Supporting pregnant women to quit smoking: postal survey of New Zealand general practitioners and midwives' smoking cessation knowledge and practices. N Z Med J. 2008;121(1270):53-65.

34. Lancaster T, Fowler G. Training health professionals in smoking cessation. Cochrane Database Syst Rev. 2000(3):CD000214. http://dx.doi. org/10.1002/14651858.

35. Abdullah AS, Stillman FA, Yang L, Luo H, Zhiyong Z, Samet JM. Tobacco use and smoking cessation practices among physicians in developing countries: a literature review (1987-2010). Int J Environ Res Public Health. 2014;11(1):429-55. doi: 10.3390/ijerph110100429.

36. GBD 2019 Tobacco Collaborators. Spatial, temporal, and demographic patterns in prevalence of smoking tobacco use and attributable disease burden in 204 countries and territories, 1990-2019: a systematic analysis from the Global Burden of Disease Study 2019. Lancet. 2021;S01406736(21)01169-7. https://doi.org/10.1016/S0140-6736(21)01169-7.

37. Norvegian Ministry of Health and Care Services. Evaluation of harm reduction as a strategic element in tobacco work. Oslo: The Ministry; 2017.

38. Cummings KM, Nahhas GJ, Sweanor DT. What is accounting for the rapid decline in cigarette sales in Japan? Int J Environ Res Public Health. 2020;17(10):3570. doi: 10.3390/ijerph17103570.

\section{Author's ORCID iD and academic degrees}

Lilia Grati, PedD, PhD Applicant - https://orcid.org/0000-0001-8678-013X

\section{Author's contribution}

LG conceptualized the idea, conducted literature review, collected the data, interpreted the data, and wrote the manuscript.

Funding. This study was supported by Ion Creanga State Pedagogical University and journal publication fee was covered by Serad Plus Firm of Production and Commerce, SRL. The author is independent and takes responsibility for the integrity of the data and accuracy of the data analysis.

Ethics approval and consent to participate

The study was approved by the Research Ethics Committee of Ion Creanga State Pedagogical University (Protocol No 285 of 16.12.2016). An informed consent from all participants in the study was obtained.

Conflict of Interests. No competing interests were disclosed. 